\title{
Discipline Policies and Preschool Special Education Students' Personal-Social Skills
}

\author{
Amanda L. Tamagni, EdD \\ Walden University, Minneapolis, Minnesota, United States \\ (iD) https://orcid.org/0000-0002-1357-1131 \\ Andrea M. Wilson, $\mathrm{PhD}$ \\ Walden University, Minneapolis, Minnesota, United States \\ (iD) https://orcid.org/0000-0002-1471-654X
}

Contact: amanda.tamagni@waldenu.edu

\begin{abstract}
Preschool special education students' lack of personal-social skills is affecting their kindergarten readiness and placing them at risk for exposure to school discipline in a large school district in the Southeastern United States. The purpose of this quantitative investigation was to examine the relationship between the quality of school discipline policies and personal-social skills of preschool special education students within the focus district. Data collection included archived personal-social skills scores, as measured by the Battelle Developmental Inventory-2 (BDI-2), of 354 preschool special education students. Four trained educators rated the effectiveness of the schools' discipline policies using the Teaching and Guidance Policy Essentials Checklist (TAGPEC). Preschool special education students' personal-social skills were measured using the BDI-2, and discipline policies were measured using the TAGPEC. Findings from simple linear regression analysis indicated no significant relationship between the TAGPEC ratings and students' BDI-2 scores. The personal-social skills for students in Title I and non-Title I schools ( $n=96$ students per group) were compared while controlling for TAGPEC ratings, but results showed no statistically significant differences. The average quality of the discipline policies was rated as inadequate overall. A policy recommendation was developed to encourage effective discipline policies and create a supportive school environment to promote positive social behaviors of all students, including the youngest and most vulnerable.
\end{abstract}

Keywords: teaching and guidance policies; challenging behavior; social skills; preschool special education; exclusionary discipline; policy recommendation

Date Submitted: December 6, 2019 | Date Published: April 16, 2020

Recommended Citation

Tamagni, A. L., \& Wilson, A. M. (2020). Discipline policies and preschool special education students' personal-social skills. Journal of Educational Research and Practice, 10, 41-54. https://doi.org/10.5590/JERAP.2020.10.1.03

\section{Introduction}

Young children with social skill deficits are often at a disadvantage when entering kindergarten and are illprepared for school (Brennan et al., 2012; Hauser-Cram \& Woodman, 2016; Whitted, 2011). Social skill deficits and challenging behavior in young children continues to be a national concern due to short- and long- 
term outcomes such as peer isolation, poor educational performance, and increased use of school discipline (Denham et al., 2013; Gilliam, 2005; Snell et al., 2012). Establishing high-quality discipline policies to support prosocial behavior in young children plays an essential role in ensuring children's preparedness for school (see Longstreth \& Garrity, 2018).

This article presents a policy recommendation based on a research study of discipline policies and preschool special education students' social skills in a very large school district in the Southeastern United States. The need for high-quality teaching and behavior guidance policies is essential as more preschool children are served on public school campuses through preschool special education programs, HeadStart programs, and voluntary preschool program (Friedman-Krauss et al., 2019; see Longstreth \& Garrity, 2018). School districts expanding services to include preschool-age children must be prepared to meet the differing developmental needs of young children by ensuring there are systems in place to support young children's social-emotional learning (Longstreth \& Garrity, 2018; Gilliam, 2016). This article offers a policy recommendation for public school districts concerned with supporting young children's school readiness and social-emotional skills.

\section{Literature Review}

Positive social behavior is one aspect of a more complex set of skills identified as social-emotional competence that plays an important role in school readiness (Denham, 2010; Denham et al., 2013). Positive social behavior includes sharing, cooperation, and effective problem solving (Denham et al., 2013). Positive social behavior in young children has significant short- and long-term consequences including improved school readiness, academic success, improved school adjustment, and reduction of challenging behavior. According to Denham's (2006) summary of the literature, children who lack positive social behavior are likely to struggle in school and experience less acceptance by peers and teachers.

Bulotsky-Shearer and Fantuzzo (2011) investigated the relationship between adult and peer interactions in preschool and later literacy outcomes. The researchers found that students with poor peer and adult interactions were more likely to have poor literacy and language outcomes in kindergarten and first grade. These findings are consistent with other research on social-emotional information processing and school success (Denham et al., 2013).

Positive social behavior also affects children's adjustment in school. Herndon et al. (2013) used regression analysis to examine the impact of preschool children's regulation and expression of negative emotions. Overall, children's ability to regulate and express negative emotions was significantly related to school adjustment (Herndon et al., 2013). The more successful children were in regulating their emotions, the better their school adjustment (Herndon et al., 2013). Promoting and supporting positive personal social skills in young children, especially children experiencing social skill delays, is a significant educational concern.

Positive social behavior is especially important for young children because of the risk of suspension and expulsion from preschool due to challenging behavior. According to Gilliam (2005), the national expulsion rate for pre-K students was 3.2 times higher than that of children in Grades K-12. The U.S. Department of Education Office for Civil Rights (2014b) found that 6\% of school districts that collected preschool discipline data reported out-of-school suspensions of at least one preschool-age child. Additionally, racial disparities in school discipline exist for preschool children. Although Black children represent 18\% of preschool enrollment, they also represent $48 \%$ of preschool children who were suspended more than once, with boys receiving three out of four out-of-school suspensions (U.S. Department of Education Office for Civil Rights, 2014a). Children who lack positive social skills and who are experiencing challenging behavior are significantly more likely to be suspended or expelled from school (Gilliam, 2005). Other researchers examined challenging behavior and early childhood expulsions. Hoover et al. (2012) surveyed early childcare providers in Colorado regarding 
their knowledge of child development, response to challenging behavior, and policies to address socialemotional competence of young children. Respondents reported that $11 \%$ of children demonstrated challenging behavior, resulting in the expulsion of 453 children (Hoover et al., 2012). The expulsion rate was 3 times higher than the K-12 expulsion rate for Colorado (Hoover et al., 2012). Even providers with many years of experience expressed a need for mental health consultation and support (Hoover et al., 2012). Supporting and promoting positive social behavior is essential at the local, state, and national level.

Developmentally appropriate, high-quality discipline policies that support positive social behavior and reduce challenging behavior in young children are a necessary and an effective component of service delivery systems (Garrity et al., 2017; U.S. Department of Education Office for Civil Rights, 2014b). Longstreth et al. (2013) examined the quality of discipline policies in state-licensed early childhood programs in in Arizona. The results showed that that the discipline policies obtained from 65 childcare sites addressed only 10 out 28 possible items, indicating that high-quality discipline policies in early childcare programs were not a priority (Longstreth et al., 2013).

There are additional national and local concerns regarding social skill deficits, exceptional young children in poverty, and inequitable school discipline policies. Students who live in poverty are more likely to be affected by harsh, punitive school discipline (Anyon et al., 2014; Mallett, 2014). Additionally, exceptional education students of color represent a larger population of students who experience harsh school discipline (Fabelo et al., 2011; Mallett, 2011). Researchers have suggested that school-level factors such as discipline policy contribute to the ongoing issue of overrepresentation of at-risk students (poor, minority, students with disabilities) in harsh school discipline outcomes (Mallett, 2014). As school districts continue to grapple with issues of school safety, discipline, and disproportionality, it is necessary to examine discipline policy and young children's personal-social skills and how these two variables are related for students who live in poverty and students who do not (Brown \& Beckett, 2006; Mallett, 2014).

\section{Developmentally Appropriate Discipline Policies}

Developmentally appropriate, fair, and equitable discipline policies contribute to positive school climates that promote prosocial behavior (Garrity et al., 2016; Gregory \& Fergus, 2017; Wang \& Degol, 2016). The Division of Early Childhood and the National Association for the Education of Young Children (2009) issued a joint policy statement to address the issue of social skill deficits and challenging behavior at a national level. The joint statement recommended early childcare providers adopt developmentally appropriate discipline policies that should address intensive individualized supports for children with challenging behavior and highlighted the importance of teaching positive social behavior to young children. The U.S. Department of Health and Human Services (2014) also issued a joint policy statement calling for the elimination of suspension and expulsion in early learning settings and emphasizing the importance of teaching positive social behavior skills. Despite these national efforts calling for high-quality, developmentally appropriate discipline policies, researchers found that early childcare systems lack high-quality discipline policies to reduce and prevent challenging behavior (Garrity et al., 2017; Longstreth et al., 2013).

Several deficits emerged from the literature surrounding early childhood and public-school discipline policies. These deficiencies included unclear definitions of suspension in early childhood (Garrity et al., 2017; Neitzel, 2018), a lack of developmentally appropriate, equitable responses to challenging behavior (Gilliam et al., 2016; Michigan State Legislature, 2016), and a lack of guidance and training for educators and administrators about resources and clear steps to take before turning to exclusionary discipline practices (Garrity et al., 2017; Gregory \& Fergus, 2017; Neitzel, 2018; Sheras \& Bradshaw, 2016; Vinh et al., 2016). There are also significant concerns, locally and nationally, about implicit bias and exclusionary discipline practices (Gilliam et al., 2016). 
Despite the call to action by the U.S. Department of Health and Human Services (2014) to reduce preschool suspension and expulsion and implement policies and practices to support positive behavior in young children, there are no clear definitions of exclusionary discipline in early childhood settings (National Center on Early Childhood Quality Assurance, 2015). When preschool suspensions and expulsions are not defined, they cannot be accurately tracked (Meek \& Gilliam, 2016; Neitzel, 2018). Some researchers have suggested that this haphazard approach in early childcare policies, tracking, and discipline decision-making may be because attendance is voluntary (Garrity et al., 2017). Therefore, there are no consistent monitoring requirements (Garrity et al., 2017; Meek \& Gilliam, 2016).

Without adequate, systematic monitoring of exclusionary discipline policies and practices, schools and districts cannot engage in problem-solving approaches to support positive behavior. Several researchers have identified the important role of data collection and analysis in preventing and addressing challenging behavior (Gilliam, 2016; Losen et al., 2015; Meek \& Gilliam, 2016; Quesenberry et al., 2011). According to Losen et al. (2015), data collection and analysis of exclusionary discipline practices enables schools and districts to identify trends and needed supports and address the root of challenging behavior.

A second deficiency in the current policy reflected in the literature is a lack of guidance and training for educators and administrators about developmentally appropriate responses to challenging behavior before turning to exclusionary discipline for young children. Policies must include resources and clear steps for educators and administrators in response to challenging behavior (Garrity et al., 2017; Gregory \& Fergus, 2017; Miller et al., 2017; Neitzel, 2018; Sheras \& Bradshaw, 2016; Vinh et al., 2016). Many states such as California, Oregon, Illinois, Connecticut, and Michigan have passed legislation to eliminate or prohibit the suspension of students in preschool through second grade, citing a need for developmentally appropriate discipline strategies for children at different developmental stages (Gregory \& Fergus, 2017). Policies must provide clear alternatives for educators and administrators to eliminate exclusionary discipline practices (Garrity et al., 2017).

The third area of concern in the current policy reflected in the literature is the role of implicit bias in school discipline. The unconscious beliefs and stereotypes that influence daily decision-making are known as implicit bias (Carter et al., 2017). Gilliam et al. (2016) examined the role of implicit bias in preschool teacher's perceptions of challenging behavior. The use of eye-tracking technology to investigate preschool teachers' implicit bias revealed that Black boys were identified as needing the most attention and that discipline approaches varied according to the teacher's race (Gilliam et al., 2016). Additionally, disproportionality in suspension and expulsion is a trend that exists in $\mathrm{K}-12$ public school environments and is mirrored in early childhood settings (U.S. Government Accountability Office, 2018; U.S. Department of Education Office for Civil Rights, 2014a). Research in K-12 environments suggests that there are several contributing factors to disproportionality in exclusionary discipline practices. These factors include poor school climate, a lack of teacher and administrator training regarding bias and perception, a lack of funding for programs, and biased implementation of discipline policies (Staats et al., 2015).

Several researchers (Devine et al., 2012; Gilliam et al., 2016; Neitzel, 2018; U.S. Department of Health and Human Services, 2014) identified a need for the development of integrated teaching and behavior guidance policies that reduce early childhood suspensions and expulsions. Teaching and guidance policies must define suspension and expulsion, as well as provide guidance and resources for educators and administrators for alternatives to exclusionary discipline (Gilliam et al., 2016; U.S. Department of Health and Human Services, 2014). Finally, policies should also address implicit bias, through highlighting culturally responsive, evidencebased teaching practices to prevent and respond to challenging behavior (Allen \& Steed, 2016; Gilliam et al., 2016; Hemmeter et al., 2016). 


\section{Theoretical Foundation}

The focus of this investigation and resulting policy recommendation was the relationship between positive personal social skills and discipline policies. The theoretical framework for the investigation and resulting policy recommendation was Bronfenbrenner's (1977) ecological systems theory which related to the present study in two ways. The first was how the theory considers the developmental processes of children. The current discipline policy in the local setting is written for the $\mathrm{K}-12$ environment and does not address developmental approaches that may contribute to an indirect effect on the personal social outcome data. According to ecological systems theory, policy, school settings, and poverty influence and are influenced by the developing child (Thapa et al., 2012). The second way the ecological systems theory relates to the current study is that it provides the framework linking policy to student outcomes through the macrosystem of school climate. The rules and norms of a school (the operationalization of the discipline policy) are considered a safety-related dimension of school climate and are part of the macrosystem that influences and is influenced by the developing child (Cohen et al., 2009; Johnston et al., 2019; Thapa et al., 2012).

\section{Method}

\section{Study of Local District}

The local district where the study took place had recently added 400 voluntary preschool seats to due to a growing concern regarding kindergarten readiness (Sokol, 2018). Although the district had redefined itself as a preschool to age 22 district instead of a $\mathrm{K}-12$ district, existing policies, including discipline policies, did not address the differentiated needs of young children, especially those identified with disabilities. Individual school improvement plans, located on the Department of Education's website, contained detailed questions about the policies and practices, including those that address student discipline. Ensuring that policies that promote district priorities and developmentally appropriate, evidence-based practices is essential in supporting the youngest learners in an area that directly affects district strategic priorities.

According to the local district strategic plan, early childhood initiatives and the reduction of suspensions are strategic priorities. However, the language in the district strategic plan addressed only K-12 environments, failing to include all preschool students, including preschool special education students. Recently, the addition of 400 free voluntary preschool seats to the existing public preschool programs on $\mathrm{K}-5$ elementary school campuses highlighted the need to ensure that current district policies align with the revised strategic plan. The existing policies did not address, nor support the positive personal-social growth of a vulnerable population. The focus of the investigation was twofold. For Research Question (RQ) 1, a correlational approach was used to examine the relationship between the quality of the discipline policies as measured by the Teaching and Guidance Policy Essentials Checklist (TAGPEC; Garrity et al., 2017) and the personal-social skills of exiting preschool special education students as measured by the Battelle Developmental Inventory-2 (BDI-2; Newborg, 2005). For RQ 2, a quasiexperimental approach was used to examine the differences between the personal social skills of two preformed groups (exiting pre-K special education students attending Title I schools and exiting pre-K special education students attending non-Title I schools) after controlling the quality of the discipline policy as measured by the TAGPEC.

\section{Participants}

The local district gave permission for the use of BDI-2 archival data for eligible preschool special education students. The state mandates that preschool special education students have a BDI-2 upon leaving pre-K special education, thereby providing the data. The following criteria were used for inclusion in this study: The elementary schools had to have preschool special education classrooms on the campus, and students had to be 
preschool special education students exiting the pre-K special education services. There were 111 elementary schools with preschool special education classes on the campus; of those schools, 61 had Title I status and 45 did not. BDI-2 scores are for students exiting pre-K special education services. The sample for RQ 1 included 354 preschool special education students who exited preschool special education services in the 2016-2017 school year, were kindergarten eligible for the next school year, but were not yet 6 years old.

For RQ 2, two balanced groups were created from the population of 354 exiting preschool special education students in the district. Two of the 111 schools did not have a school improvement plan and could not be included in the analysis, bringing the total to 109 schools. The groups were created by listing the BDI-2 scores of the students from all 45 Title I schools (96 students). An equal number of students (96) was randomly selected 96 students from 45 non-Title I schools using a random number generator. Because balanced groups were created from the total population used in RQ $1(N=354)$, the sample for RQ 2 included the same students. There two groups of 96 students for a total of 192 students.

\section{Procedure}

The current investigation of the discipline policies and practices in the local district began with examining school improvement plans. School improvement plans were used because they are public data, and the template requires the school to provide detailed, individualized information about school environments, culture, and discipline policies. For example, in the first section of the plan that addresses current school status, the school is required to describe the school environment, culture, relationships, behavior systems, discipline, and training on behavior systems. The section also requires the school explain how the socialemotional learning needs of the students are being met. It requires a description of the problem-solving processes through multitiered systems of support. It is noteworthy that each school's response to this section was an identical description of the problem-solving model for data analysis and most lacked specificity regarding how social-emotional learning needs were addressed.

Four educators with a minimum of 5 years' experience in early childhood education completed the TAGPEC to score the discipline policies. All four educators were trained at the same time in the use of the instrument to calculate a score for each school's discipline policy. The raters were trained using training materials created by the authors and available on their website for no cost. Each rater received copies of the book (Longstreth \& Garrity, 2018) which contained detailed scoring directions and examples. The panel of raters completed the ratings of the discipline policies within the same time frame. Raters assigned a point value of zero to items marked no, one to items marked sometimes, and a value of two to items marked yes. Deidentified BDI-2 data were obtained with permission from the local district.

\section{Measures}

The BDI-2 is a criterion-referenced, standardized assessment used to measure developmental skills of children aged birth to 7 years, 11 months (Newborg, 2005). The BDI-2 screener is a shortened version of the full assessment and is used in several states, including Florida, as a program outcome measure for preschool special education programs (Elbaum et al., 2010). There are five developmental domains assessed by the BDI2 including Adaptive, Personal-Social, Communication, Cognitive, and Motor. Additionally, the current study addressed the growing local concern that students who were entering kindergarten were not ready for kindergarten. Based on the research conducted, the recommendations in this article were developed.

According to Garrity et al. (2017), the TAGPEC is a 30-item checklist that can be used by a variety of early childcare program providers (state funded, faith based, for-profit, nonprofit, etc.) to evaluate the quality of discipline policies. The 30 items on the checklist assist users in rating the seven essential features of a discipline policy. There is a rating system for each item on the TAGPEC. Items can be marked "no" if the 
feature was not addressed in the policy, "emerging" if there was minimal evidence of the feature in the policy, or "yes" if there was clear evidence of the feature in the policy. Ratings are assigned as follows: o points for items marked "no," 1 point for items marked as "emerging," and 2 points for items marked "yes." The highest score on the TAGPEC is 6o. This score indicates sufficient evidence of each of the essential features in the discipline policy.

\section{Results}

The approach for the investigation was correlational and quasiexperimental (see Lodico et al., 2010) and examined the relationship between the quality of the discipline policies as measured by the TAGPEC (Garrity et al., 2017) and the personal-social skills of exiting preschool special education students as measured by the BDI-2. Data collection included the four raters' TAGPEC scores of the discipline policies and archived personal-social skills scores, as measured by the BDI-2, of 354 preschool special education students. Fleiss's Kappa reliability estimate was used to measure agreement between the raters who completed the TAGPEC. There was fair agreement between the rater's scores, $\kappa=.206,95 \%$ confidence interval (CI) [0.159, 0.252], $p<.001$.

Results for RQ 1 were calcualted through a linear regression analysis in SPSS Version 24 to assess whether TAGPEC scores significantly predicted Personal Social BDI-2 scores. Table 1 shows the descriptive statistics relative to the sample. The predictor variable was not found to be statistically significant, $B=0.93,95 \%$ CI [$1.15,3.01], p=.38$. The TAGPEC scores did not explain a significant proportion of the variation in the Personal Social BDI-2 scores.

Table 1. Descriptive Statistics for Personal Social and Teaching and Guidance Policy Essentials Checklist (TAGPEC) Scores

\begin{tabular}{lccc}
\hline \multicolumn{1}{c}{ Measure } & $\boldsymbol{M}$ & $\boldsymbol{S D}$ & $\boldsymbol{N}$ \\
\hline $\begin{array}{l}\text { Personal Social raw score } \\
\text { on BDI-2 }\end{array}$ & 33.95 & 5.75 & 354 \\
TAGPEC score & .88 & .29 & 354 \\
\hline
\end{tabular}

Note. BDI = Battelle Developmental Inventory-2.

Due to the increased risk of exposure to school discipline for students living in poverty found in the literature, an analysis of covariance was used to compare BDI-2 scores of students in Title I and non-Title I schools ( $n=$ 96 students per group) while conrolling for TAGPEC ratings. The results of the analysis of covariance were not significant, $F(2,188)=0.29, p=.75$, indicating any differences in values of BDI-2 between Title 1 and nonTitle 1 schools were not likely to be due to anything beyond chance. The main effect, Title 1 status was not significant at the $95 \% \mathrm{CI}, F(1,188)=0.10, p=.76$, indicating there were no significant differences of Personal Social BDI-2 scores by Title 1 status levels. There were no differences in personal-social skills as measured by the BDI-2 between students in Title I versus non-Title I schools.

Despite the inclusion of detailed elements regarding the school's problem-solving processes, the overall quality of the 109 school discipline policies was rated as inadequate using the TAGPEC. The nonsignificant findings pointed to the ineffectiveness and poor quality of the current discipline policy. The results were consistent with prior research in the private childcare sector on the quality of discipline policies (Garrity et al., 2016) and led to a policy recommendation. 
Tamagni \& Wilson, 2020

\section{Discussion}

\section{Policy Recommendations}

The policy recommendations derived from the research study offer alternatives for districts and early childhood programs to address deficiencies in school discipline policies. In publicly available district strategic plans, most district policies continue to focus on the $\mathrm{K}-12$ environment. This policy recommendation is based on evidence from the literature which indicates there are seven essential features of high-quality, early childhood teaching and guidance policies that focus on the prevention of exclusionary discipline practices, such as suspension, reduce discipline disparities across race and gender, and emphasize helping students improve positive behavior (Longstreth \& Garrity, 2018). School improvement plans follow a template format located on the state Department of Education website (Florida Department of Education, 2019) and contain policies with related features, such as emphasizing positive school climate, and data-based problem-solving processes. However, they do not include clear definitions of suspension in early childhood, developmentally appropriate, equitable responses to challenging behavior, or guidance regarding the role implicit bias plays in exclusionary discipline practices.

\section{Clear Definitions of Suspension and Expulsion in Early Childhood}

Out-of-school suspension is defined as time students spend out of school for behavioral or conduct infractions (Skiba et al., 2014). According to Neitzel (2018), this definition may not capture the range of exclusionary discipline practices used in early childhood in which students are removed from instruction as an adult response to challenging behavior. Students are often sent home for the day (parent pick-up), sent to another classroom, or otherwise excluded from instruction (Neitzel, 2018). As is the case with many school districts, data on early childhood suspension and expulsions are not captured or reported. In the current study, school improvement plans did not include early childhood teaching and guidance policies or practices to prevent exclusionary discipline. Although most school districts have established codes of conduct, and data tracking systems for exclusionary discipline, the policies are written for K-12 environments (Florida Department of Education, 2019). The data must be collected and reported to have an impact on reducing the use of exclusionary discipline practices. The recommendation, based on the current study, is that school districts concerned with supporting school readiness in young children develop a teaching and guidance policy, using the seven essential elements outlined by Longstreth and Garrity (2018).

Additionally, the teaching and guidance policy must include clear definitions of exclusionary discipline, including soft suspensions. Exclusionary discipline practices must be defined and eliminated for preschool through second grade due to the serious short and long-term consequences (Gilliam et al., 2016; U.S. Department of Health and Human Services, 2014). The policy must also address consistent data collection and reporting of early childhood discipline data (Essential Feature 7; see Longstreth \& Garrity, 2018).

\section{Responses to Challenging Behavior}

Across the United States, school districts have updated discipline policies in K-12 environments to address developmentally appropriate responses to challenging behavior, including the revision of zero-tolerance policies (Gregory \& Fergus, 2017). The recommendation, based on the current study, is that the early childhood teaching and guidance policy include evidence-based resources for educators and administrators to support positive personal-social behavior and respond to challenging behavior (see Longstreth \& Garrity, 2018; Essential Features 1-4). The teaching and guidance policy should contain information about district professional development on evidence-based practices, such as the pyramid model (Hemmeter et al., 2016). It should also include hyperlinks in the document to internal district resources, as well as state and national resources designed to prevent and respond to challenging behavior, such as the Technical Assistance and 
Training System (https://tats.ucf.edu/) and the National Center for Pyramid Model Innovations (http://challengingbehavior.cbcs.usf.edu). Finally, as an additional resource, school districts should create an early childhood multidisciplinary district team to provide behavioral consultation and assistance to schools, educators, and administrators. Like many districts focused on continuous improvement, the local district has existing multidisciplinary teams to support $\mathrm{K}-12$ schools and students. Districts concerned with improving young children's school readiness could incorporate this recommendation into existing structures by expanding it to include preschool age students. According to several researchers (Garrity et al., 2017; Gilliam, 2016; Hemmeter et al., 2016), access to mental consultation and behavioral supports is an essential step in implementing evidence-based practices with fidelity to reduce challenging behaviors that may result in exclusionary discipline.

\section{Addressing the Role of Implicit Bias}

Racial disparities in exclusionary discipline in the preschool-12 environment are well-documented in the literature (Gilliam, 2016; Gilliam et al., 2016; Skiba et al., 2014). The short and long-term effects of such practices are so concerning that U.S. Department of Health and Human Services (2014) issued a joint policy statement calling for the severe limitation of exclusionary discipline practices in early childhood settings. The joint statement also included recommendations for creating clear policies and expectations for supporting positive social behavior as well as ensuring equity and fairness. The recommended alternative to the current policy is found in Longstreth and Garrity's (2018) essential features for high-quality early childhood discipline policies. The policy must ensure the data collection and analysis process includes a program-wide analysis of disaggregated discipline data to be reviewed regularly. Additionally, the policy should include professional development recommendations and resources for teachers and administrators on topics related to preventing and responding to challenging behavior, including implicit bias (Gilliam et al., 2016; see Longstreth \& Garrity, 2018).

\section{Recommended Course of Action}

The current policy recommendation takes the position, aligned with recommendations from the current literature and present study, that high-quality, early childhood discipline policies should provide clear definitions of, and evidenced-based, equitable, alternatives to, exclusionary discipline practices (Gilliam, 2016; see Longstreth \& Garrity, 2018; U.S. Department of Health and Human Services, 2014). The alternative recommended for districts with current policies that do not address preschool age students, is to develop an early childhood teaching and guidance policy using the seven essential features (see Longstreth \& Garrity, 2018) of effective discipline policies. The policy can be developed by a team of early childhood personnel including supervisors, coordinators, teachers, school principals, and preschool special educators. The team should also include representation from the district special education department to ensure that any policy developed aligns with district strategic plans. The potential implication of creating and implementing this policy with fidelity is that preschool special education students will improve their personal-social skills. A second implication is that all preschool students on district campuses will benefit from high-quality, effective teaching and guidance policies to support positive behavior. The vehicle for this change is through improved school climates that result from providing educators and administrators clear guidance and resources to support children's positive personal-social skills.

The policy recommendation would not require any additional funding for implementation and would fit well with school improvement plans. Many districts such as this have multidisciplinary teams and processes in place to support schools and students. Additionally, structures and supports for communicating new policy to schools and administrators also exist in many districts like this one. Therefore, no additional funding or structures would be needed to implement this policy recommendation. 


\section{Policy Change Evaluation}

Two methods can be used to evaluate the effectiveness of a policy change proposal like this one. The first method is a goal-based evaluation of the teaching and guidance policy. Longstreth and Garrity (2018) recommend that programs set short- and long-term goals for the development and implementation of highquality teaching and guidance policies. A short-term goal (3 months) for districts would be to create an early childhood teaching and guidance policy based on Longstreth and Garrity's seven essential features. The policy should include the elimination of suspension and expulsion of children in preschool through second grade. The long-term goal (1 year) would be to embed the policy into existing professional development opportunities for educators and administrators.

The second method of evaluation is to examine the influence of the teaching and guidance policy. Like many districts, the local district has an early childhood team that can examine student outcomes on a quarterly basis using district behavior tracker data and Teaching Strategies Gold (Lambert et al., 2015) data in the socialemotional domain. Behavior tracker is a tool used in the districtwide multitiered systems of support and response to intervention process for $\mathrm{K}-12$ and was recently revised to include preschool students. Teaching Strategies Gold (Lambert et al., 2015) is an online portfolio assessment tool used in early childhood programs in the local district. These two methods to evaluate the policy change will provide goals for a plan of action as well as student outcome data.

\section{Conclusion}

High-quality teaching and guidance policies are a necessary first step for improving student outcomes and reducing racial discipline disparities (Gilliam, 2016; Gregory \& Fergus, 2017; see Longstreth \& Garrity, 2018; U.S. Department of Health and Human Services, 2014). Teaching and guidance policies that define exclusionary discipline include developmentally responses to challenging behavior and address implicit bias through ongoing progress monitoring will improve outcomes for a vulnerable population. The current policy, as in many similar districts, does not include or address the needs of the 3,00o preschool special education students found on local district $\mathrm{K}-5$ elementary school campuses. The teaching and guidance policy can provide clear guidance and resources for educators and administrators to support preschool special education students and all early childhood students (Gilliam, 2016; see Longstreth \& Garrity, 2018).

\section{References}

Allen, R., \& Steed, E. A. (2016). Culturally responsive pyramid model practices: Program-wide positive behavior support for young children. Topics in Early Childhood Special Education, 36(3), 165-175. https://doi.org/10.1177/0271121416651164

Anyon, Y., Jenson, J. M., Altschul, I., Farrar, J., McQueen, J., Greer, E., Downing, B., \& Simmons, J. (2014). The persistent effect of race and the promise of alternatives to suspension in school discipline outcomes. Children \& Youth Services Review, 44(1), 379-386. https://doi.org/10.1016/j.childyouth.2014.06.025

Brennan, L. M., Shaw, D. S., Dishion, T. J., \& Wilson, M. (2012). Longitudinal predictors of school-age academic achievement: Unique contributions of toddler-age aggression, oppositionality, inattention, and hyperactivity. Journal of Abnormal Child Psychology, 4o(8), 1289-1300. https://doi.org/10.1007/s10802-012-9639-2

Bronfenbrenner, U. (1977). Toward an experimental ecology of human development. American Psychologist,32(7), 513-531. https://doi.org/10.1037/0003-066X.32.7.513 
Brown, L. H., \& Beckett, K. S. (2006). The role of the school district in student discipline: Building consensus in Cincinnati. The Urban Review, 38(3), 235-256. https://doi.org/10.1007/s11256-006-0032-8

Bulotsky-Shearer, R. J., \& Fantuzzo, J. W. (2011). Preschool behavior problems in classroom learning situations and literacy outcomes in kindergarten and first grade. Early Childhood Research Quarterly, 26(1), 61-73. https://doi.org/10.1016/j.ecresq.2010.04.004

Carter, P. L., Skiba, R., Arrendondo, M. I., \& Pollock, M. (2017). You can't fix what you don't look at: Acknowledging race in addressing racial discipline disparities: Urban Education, 52(5), 207-235. https://doi.org/10.1177/0042085916660350

Cohen, J., McCabe, L., Michelli, N. M., \& Pickeral, T. (2009). School climate: Research, policy, practice, and teacher education. Teachers College Record, 111(1) 180-213.

Denham, S. (2006). Social-emotional competence as support for school readiness: What is it and how do we assess it? Early Education \& Development, 17(1), 57-89.

https://doi.org/10.1207/s15566935eed1701_4

Denham, S. (2010). "Plays nice with others": Social-emotional learning and academic success. Early Education and Development, 21(5), 652-680. https://doi.org/10.1080/10409289.2010.497450

Denham, S. A., Kalb, S., Way, E., Warren-Khot, H., Rhoades, B. L., \& Bassett, H. H. (2013). Social and emotional information processing in preschoolers: Indicator of early schoolsuccess. Early Child Development and Care, 183(5), 667-688. https://doi.org/10.1080/03004430.2012.682728

Devine, P. G., Forscher, P. S., Austin, A.J., \& Cox, W.T. (2012). Long-term reduction in implicit race bias: A prejudice habit-breaking intervention. Journal of Experimental Psycyology, 48(6), 1267-1278. https://doi.org/10.1016/j.jesp.2012.06.003

Division of Early Childhood and the National Association for the Education of Young Children. (2009). Early childhood inclusion: A joint position statement of the Division for Early Childhood (DEC) and the National Association for the Education of Young Children (NAEYC). The University of North Carolina, FPG Child Development Institute. https://www.naeyc.org/files/naeyc/file/positions/DEC NAEYC EC updatedKS.pdf

Elbaum, B., Gattamorta, K. A., \& Penfield, R. D. (2010). Evaluation of the Battelle Developmental Inventory 2nd edition, screening test for use in state's child outcomes measurement systems under the Individual with Disabilities Education Act. Journal of Early Intervention, 12(4), 255-273. https://doi.org/10.1177/1053815110384723

Fabelo, T., Thompson, M. D., Plotkin, M., Carmichael, D., Marchbanks, M. P., III, \& Booth, E. A. (2011). Breaking school's rules: A statewide study of how school discipline relates to student's success and juvenile justice involvement. Council of State Governments Justice Center; Public Research Policy Research Institute of Texas A \& M University. https://csgjusticecenter.org/wpcontent/uploads/2012/o8/Breaking_Schools_Rules_Report_Final.pdf

Florida Department of Education. (2019). Continuous Improvement Systems (CIMS). https://www.floridacims.org/

Friedman-Krauss, A. H., Barnett, S. W., Garver, K. A., Hodges, K. S., Weisenfeld, G. G., \& DiCrecchio, N. (2019). The state of preschool yearbook 2018. http://nieer.org/wpcontent/uploads/2019/05/YB2018 Executive-SummaryR.pdf

Garrity, S. M., Longstreth, S. L., \& Linder, L. K. (2017). An examination of the quality of discipline policies in NAEYC-accredited early care and education programs. Topics in Early Childhood Special Education,37(2), 94-106. https://doi.org/10.1177/0271121416672185 
Garrity, S. M., Longstreth, S. L., Salcedo-Potter, N., \& Staub, A. (2016). Using the teaching and guidance policy essentials checklist to build and support effective early childhood systems. Early Childhood Education Journal, 44(3), 209-216. https://doi.org/ 10.1007/s10643-015-0713-6

Gilliam, W. S. (2005). Prekindergarteners left behind: Expulsion rates in state prekindergarten systems. Foundation for Child Development. http://www.hartfordinfo.org/issues/wsd/education/NationalPreKExpulsionPaper.pdf

Gilliam, W. S. (2016). Early childhood expulsions and suspensions undermine our nation's most promising agent of opportunity and social justice. https://www.issuelab.org/resource/early-childhoodexpulsions-and-suspensions-undermine-our-nation-s-most-promising-agent-of-opportunity-andsocial-justice.html

Gilliam, W. S., Maupin, A., Reyes, C., Accavitti, M., \& Shic, F. (2016). Early childhood mental health consultation: Results of a statewide random-controlled evaluation. Journal of American Academy of Child \& Adolescent Psychiatry, 55(9), 754-761. https://doi.org/10.1016/j.jaac.2016.06.006

Gregory, A., \& Fergus, E. (2017). Social and emotional learning and equity in school discipline. The Future of Children, 27(1), 117-136. https://doi.org/10.1353/foc.2017.0006

Hauser-Cram, P., \& Woodman, A. C. (2016). Trajectories of internalizing and externalizing behavior problems in children with developmental disabilities. Journal of Abnormal Child Psychology, 44(4), 811-821. https://doi.org/10.1007/s10802-015-0055-2

Hemmeter, M. L., Snyder, P. A., Fox, L., \& Algina, J. (2016). Evaluating the implementation of the pyramid model for promoting social-emotional competence in early childhood classrooms. Topics in Early Childhood Special Education 36(3), 133-146. https://doi.org/10.1177/0271121416653386

Herndon, K. J., Bailey, C. S., Shewark, E. A., Denham, S. A., \& Bassett, H. H. (2013). Preschoolers' emotion expression and regulation: Relations with school adjustment. The Journal of Genetic Psychology, 174(6), 642-663. https://doi.org/10.1080/00221325.2012.759525

Hoover, S. D., Kubicek, L. F., Rosenberg, C. R., Zundel, C., \& Rosenberg, S. A. (2012). Influence of behavioral concerns and early childhood expulsions on the development of early childhood mental health consultation in Colorado. Infant Mental Health Journal, 33(3), 246-255. https://doi.org/10.1002/imhj.21334

Johnston, C. B., Herzog, T. K., Hill-Chapman, C. R., Siney, C., \& Fergusson, A. (2019). Creating positive learning environments in early childhood using teacher-generated prosocial lessons. Journal of Educational Research and Practice, 9(1), 132-145. https://doi.org/10.5590/JERAP.2019.09.1.10

Lambert, R., Kim, D., \& Burts, D. (2015). The measurement properties of the Teaching Strategies GOLD assessment system. Early Childhood Research Quarterly, 33(4), 49-63. https://doi.org/O.1016/j.ecresq.2015.05.004

Lodico, M. G., Spaulding, D. S., \& Voegtle, K. H. (2010). Methods in educational research: From theory to practice. Jossey-Bass.

Longstreth, S., Brady, S., \& Kay, A. (2013). Discipline policies in early care and education programs: Building an infrastructure for social and academic success. Early Education and Development, 24(2), 253271. https://doi.org/10.1080/10409289.2011.647608

Longstreth, S., \& Garrity, S. (2018). Effective discipline policies: How to create a system that supports young children's social-emotional competence. Gryphon House. 
Losen, D. J., Hodson, C. L., Keith, II, M. A, Morrison, K., \& Belway, S. (2015). Are we closing the school discipline gap? UCLA: The Civil Rights Project/Proyecto Derechos Civiles. http://escholarship.org/uc/item/2t36g571

Mallett, C. A. (2011). Seven things juvenile courts should know about learning disabilities. National Council of Juvenile and Family Court Judges. http://engagedscholarship.csuohio.edu/cgi/viewcontent.cgi?article $=1003 \&$ context=clsowo facpub

Mallett, C. A. (2014). The school-to-prison pipeline: Disproportionate impact on vulnerable children and adolescents. Education and Urban Society, 49(6), 563-592. https://doi.org/10.1177/0013124516644053

Meek, S. E., \& Gilliam, W. S. (2016). Expulsion and suspension in early education as matters of social justice and health equity. NAM Perspectives, 6, 10. https://doi.org/10.31478/201610e

Michigan State Legislature. (2016). Legislative analysis: Changes to suspension and expulsion rules in schools. http://www.legislature.i.gov/documents/2015-2016/billanalysis/House/pdf/2015-HLA5618-B4A00637.pdf

Miller, S., Smith-Bonahue, T., \& Kemple, K. (2017). Preschool teachers' response to challenging behavior: The role of organizational climate in referrals and expulsions. International Research in Early Childhood Education, 8(1), 38-57. https://eric.ed.gov/?id=EJ1173675

National Center on Early Childhood Quality Assurance. (2015). Research Brief\#1: Trends in childcare center licensing regulations and policies for 2014. https://www.naralicensing.org/2014-cc-licensing-study

Neitzel, J. (2018). Research to practice: Understanding the role of implicit bias in early childhood disciplinary practices. Journal of Early Childhood Teacher Education, 39(3), 232-242.

https://doi.org/10.1080/10901027.2018.1463322

Newborg, J. (2005). Battelle Developmental Inventor: Examiner's manual (2nd ed). Riverside.

Quesenberry, A. C., Hemmeter, M. L., \& Ostrosky, M. M. (2011). Addressing challenging behaviors in head start: A closer look at program policies and procedures. Topics in Early Childhood Special Education, 3O(4), 209-219. https://doi.org/10.1177.0271121410371985

Sheras, P. L., \& Bradshaw, C. P. (2016). Fostering policies that enhance positive school environment. Theory into Practice, 55(2), 129-135. https://doi.org/10.1080/00405841.2016.1156990

Skiba, R. J., Chung, C. G., Trachok, M., Baker, T. L., Sheya, A., \& Hughes, R. L. (2014). Parsing disciplinary disproportionality contributions of infraction, student, and school characteristics to out-of-school suspension and expulsion. American Educational Research Journal, 51(4), 640-670. https://doi.org/10.3102/0002831214541670

Snell, M. E., Voorhees, M. D., Berlin, R. A., Stanton-Chapman, T., Hadden, S., \& McCarty, J. (2012). Use of interview and observation to clarify reported practices of head start staff concerning problem behavior: Implications for programs and training. Journal of Positive Behavior Interventions, 14(2), 108-117. https://doi.org/10.1177/1098300711416819

Sokol, M. (2018, February). Are you ready Freddy? Tampa Bay Times. https://www.tampabay.com/blogs/gradebook/2018/02/06/are-you-ready-freddy/

Staats, C., Capatosto, K., Wright, R. A., \& Contractor, D. (2015). State of the science: Implicit bias review 2015. Kirwin Institute of the Study of Race and Ethnicity. http://kirwaninstitute.osu.edu/wpcontent/uploads/2015/05/2015-kirwan-implicit-bias.pdf 
Thapa, A., Cohen, J., Higgins-D’Alessandro, A., \& Guffey, S. (2012). School climate research summary: August 2012 (School Climate Brief, No. 3). National School Climate Center. https://doi.org/10.3102/0034654313483907

U.S. Department of Education Office for Civil Rights. (2014a). Civil rights data collection: Data snapshot: School discipline (Issue Brief Number 1). http://ocrdata.ed.gov/Downloads/CRDC-School-DisciplineSnapshot.pdf

U.S. Department of Education Office for Civil Rights. (2014b). Civil rights data collection: Data snapshot: School discipline (Issue Brief Number 2). https://www2.ed.gov/about/offices/list/ocr/docs/crdcearly-learning-snapshot.pdf

U.S. Department of Health and Human Services. (2014). Policy statement on expulsion and suspension policies in early childhood settings. https://wwww.acf.hhs.gov/sites/default/files/ecd/expulsion suspension final.pdf

U.S. Government Accountability Office. (2018). Discipline disparities for Black students, boys, and students with disabilities (Publication No. 18-258). United States Government Printing Office. https://www.gao.gov/products/GAO-18-258

Vinh, M., Strain, P., Davidon, S., \& Smith, B. J. (2016). One state's systems change efforts to reduce childcare expulsion: Taking the pyramid model to scale. Topics in Early Childhood Special Education, 36(3), 159-164. https://doi.org/10.1177/0271121415626130

Wang, M. M., \& Degol, J. (2016). School climate: A review of the construct, measurement, and impact on student outcomes. Educational Psychology Review, 28(2), 315-352. https://doi.org/10.1007/s10648-015-9319-1

Whitted, K. S. (2011). Understanding how social and emotional skill deficits contribute to school failure. Preventing School Failure, 55(1), 10-16. https://doi.org/10.1080/10459880903286755

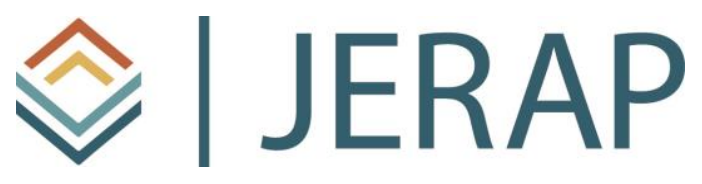

The Journal of Educational Research and Practice is a peerreviewed journal that provides a forum for studies and dialogue about developments and change in the field of education and learning. The journal includes research and related content that examine current relevant educational issues and processes. The aim is to provide readers with knowledge and with strategies to use that knowledge in educational or learning environments. JERAP focuses on education at all levels and in any setting, and includes peer-reviewed research reports, commentaries, book reviews, interviews of prominent individuals, and reports about educational practice. The journal is sponsored by the Richard W. Riley College of Education and Leadership at Walden University, and publication in JERAP is always free to authors and readers. 